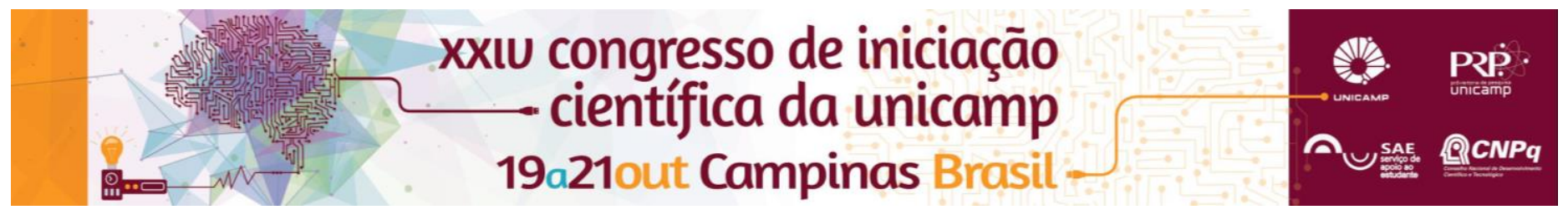

\title{
"Efeito do uso prévio de enxaguatórios contendo peróxido de hidrogênio na resistência de união de diferentes sistemas adesivos e morfologia da dentina."
}

\section{Carolina G. Barbosa*, Waldemir F. Vieira-Junior, Jéssica D. Theobaldo, Débora A.N.L. Lima, Flávio H.B. Aguiar.}

\section{Resumo}

Os efeitos de enxaguatórios contendo peróxido de hidrogênio $(\mathrm{PH})$ na dentina são desconhecidos. Objetivo: Avaliar o efeito do uso prévio de enxaguatórios contendo peróxido de hidrogênio na resistência de união (RU) de diferentes sistemas adesivos à dentina. Métodos: 72 áreas de dentina bovina $(5 \times 5 \mathrm{~mm})$ foram aleatoriamente divididas em 6 protocolos de tratamento ( $n=12$ ) por 21 dias: A) G1 e G2 - água destilada; B) G3 e G4 - Colgate Plax Whitening $B$ (PW); e C) G5 e G6 - Colgate Luminous White ${ }^{\circledR}$ (LW). Após esse protocolo, os blocos foram restaurados com os sistemas adesivos Single Bond 2 (SB) (G1, G3 e G5) ou Clearfil SE Bond (CSEB) (G2, G4 e G6) e submetidos ao teste de microcisalhamento (Mpa). Durante todo o experimento, as amostras foram armazenadas em saliva artificial. Após exposição aos enxaguatórios as amostras foram submetidas à Microscopia Eletrônica de Varredura (MEV) para obtenção de imagens da morfologia superficial da dentina. Os dados obtidos foram submetidos ao teste estatístico ANOVA 2 fatores e Tukey. Resultados: PW reduziu os valores de RU para o sistema adesivo SB. CSEB teve os valores de RU aumentados após a exposição à enxaguatórios contendo pirofosfatos. Conclusão: Enxaguatório contendo somente $\mathrm{PH}$ reduz a resistência de união de um sistema adesivo convencional, enquanto que enxaguatório contendo pirofosfatos em sua composição aumenta os valores de resistência de união para adesivos autocondicionantes. Os enxaguatórios alteram a morfologia superficial da dentina.

\section{Palavras-chave:}

Antisséptico bucal, peróxido de hidrogênio, microcisalhamento.

\section{Introdução}

Produtos OTC ("over-the-counter") são de fácil acesso ao paciente e têm como proposta promover o "clareamento dental" devido à presença do peróxido de hidrogênio $\left(\mathrm{H}_{2} \mathrm{O}_{2}\right)$, entretanto sua eficácia é questionada. $\mathrm{O}$ $\mathrm{H}_{2} \mathrm{O}_{2}$ possui um efeito oxidativo inespecífico podendo causar alterações morfológicas na estrutura dental e reduzir a força de adesão em restaurações. O objetivo desse estudo foi avaliar o efeito do uso prévio de enxaguatórios contendo $\mathrm{H}_{2} \mathrm{O}_{2}$, acrescidos de pirofosfatos ou não, na resistência de união de diferentes sistemas adesivos à dentina.

\section{Resultados e Discussão}

A partir das imagens obtidas por MEV nota-se que o uso de enxaguatório PW causou alteração morfológica caracterizando dissolução mineral quando comparado ao grupo controle. Enxaguatórios contendo $\mathrm{H}_{2} \mathrm{O}_{2}+$ Pirofosfato (P) induzem a formação de precipitados na superfície dentinária, apresentando topografia superficial similar ao grupo controle.

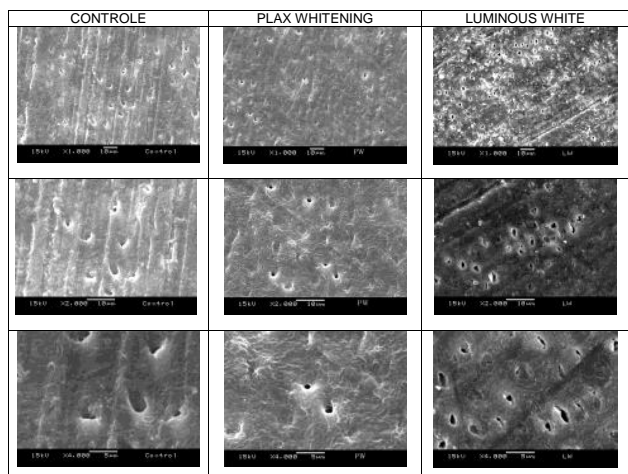

Figura 1. Imagens obtidas por Microscopia Eletrônica de Varredura (MEV) para análise superficial da dentina exposta ou não à enxaguatórios. Obtenção das imagens nos aumentos: 1000X; 2000X; 4000X.
PW reduziu os valores de RU para o sistema adesivo SB. CSEB aumentou os valores de RU à dentina após o uso de enxaguatórios.

Tabela 1. Média (desvio padrão) da resistência de união (Mpa) de dois sistemas adesivos em função da exposição prévia da dentina à enxaguatórios.

\begin{tabular}{|c|c|c|}
\hline Tratamento & SB & CSEB \\
\hline Sem enxaguatório & $10,7(4,4) \mathrm{Ab}$ & $7,0(3,5) \mathrm{Aa}$ \\
\hline PW $\left(1,5 \% \mathrm{H}_{2} \mathrm{O}_{2}\right)$ & $4,7(1,6) \mathrm{Aa}$ & $8,7(4,6)$ Aab \\
\hline LW $\left(2 \% \mathrm{H}_{2} \mathrm{O}_{2}+\mathrm{P}\right)$ & $8,4(2,6) \mathrm{Ab}$ & $13,3(6,3) \mathrm{Ab}$ \\
\hline
\end{tabular}

O oxigênio residual reativo proveniente do $\mathrm{PH}$ e alterações orgânicas e inorgânicas da dentina pode comprometer a difusão do sistema adesivo por meio dos espaços interfibrilares na rede de colágeno, reduzindo a resistência de união à dentina.

\section{Conclusões}

Enxaguatório contendo somente $\mathrm{PH}$ reduz à resistência de união de um sistema adesivo convencional, enquanto que enxaguatório contendo pirofosfato aumenta a adesão de adesivo autocondicionante à dentina. Os enxaguatórios alteram a morfologia superficial da dentina.

\section{Agradecimentos}

Este estudo foi financiado pelo CNPQ - PIBIC. 